\title{
Treatment of Recurrent Respiratory Papillomatosis Using Laser and Available Adjuvant Therapies
}

\author{
Seung Hoon Woo \\ Phil-Sang Chung \\ Sang Joon Lee
}

Department of Otorhinolaryngology-Head \& Neck Surgery, Dankook University College of Medicine, Cheonan, Korea

\section{Correspondence}

Sang Joon Lee

Department of Otorhinolaryngology-Head and Neck Surgery, Dankook University College of Medicine, 119 Dandae-ro, Cheonan 31116, Korea Tel.: +82-41-550-3975

Fax: +82-41-556-1090

E-mail: Isj72@dankook.ac.kr

(C) Korean Society for Laser Medicine and Surgery

(c) This is an open access article distributed under the terms of the Creative Commons Attribution NonCommercial License (http://creativecommons.org/ licenses/by-nc/4.0) which permits unrestricted noncommercial use, distribution, and reproduction in any medium, provided the original work is properly cited.

\begin{abstract}
Recurrent respiratory papillomatosis (RRP) is a benign tumor that occurs in the respiratory tract, especially in the larynx. The etiology of RRP is human papillomavirus (HPV). According to the age of occurrence, RRP is divided into childhood-onset and adult-onset types. Generally, childhoodonset RRP shows a high recurrence rate and diffuse involvement in the respiratory tract. Adult-onset RRP is more localized and appears more frequently as a solitary lesion. It may be the result of sexual transmission or the proliferation of latent HPV infections. At present, the treatment of choice for RRP is $\mathrm{CO}_{2}$ laser ablation. In addition, pulse dye laser or KTP (KTiOPO: potassium-titanyl-phosphate) lasers are also used. Nonsurgical adjuvant therapies can be applied in cases requiring repetitive surgery or with diffuse extensions. This review will introduce the clinical features of RRP and various treatment options including lasers.
\end{abstract}

\section{Key words}

Recurrent respiratory papillomatosis; Human papillomavirus; Laser 


\section{INTRODUCTION}

Recurrent respiratory papillomatosis (RRP) is the most common benign tumor occurring in children and is hard to treat because it has a high recurrence rate and can spread anywhere, not only to the larynx but also to every part of the respiratory tract, from the nasal cavity to the bronchial trees. Clinically, it is divided into childhoodonset and adult-onset types. Childhood-onset RRP tends to invade multiple anatomic sites, show a progressive disease, and needs repetitive surgeries due to recurrence unlike adult-onset RRP. ${ }^{1}$ This report describes the clinical characteristics of RRP and introduces surgical and nonsurgical adjuvant treatments.

\section{EPIDEMIOLOGY AND CLINICAL CHARACTERISTICS}

Human papillomavirus (HPV), with more than 170 species, is a DNA virus that selectively infects keratinocytes in the skin or mucous membranes. The most common types found in airways are HPV 6 and HPV 11. In general, HPV 11 shows a worse prognosis. ${ }^{2}$ HPV 6 and 11 can also be found as simultaneous infections. HPV 6 and 11 are known to have a low risk of malignancy, whereas HPV 16 and 18 are more likely to be related to malignancy.

The pathways of HPV infection in children are thought to be vertical infections at birth through an HPV-infected birth canal. Approximately 50\% of the patients with childhood-onset RRP reported that their mothers had condyloma acuminate, which is related to HPV 6 and 11 , at the time of birth. RRP shows a higher incidence rate in natural vaginal childbirth than in cesarean section, in first babies, and in young mothers more recently infected with HPV. ${ }^{3}$

The most common site of RRP is the vocal folds, and voice changes such as hoarseness and weak crying are the most common symptoms. In severe cases, stridor can develop. The progression of RRP is difficult to predict, and sometimes it disappears or progresses slowly, but it can get worse rapidly. Tracheostomy should be avoided because it can worsen RRP, and extubation should be tried as soon as possible if tracheostomy has been performed. Intubation should also be avoided as it can cause mechanical dissemination, which can lead to the progression of RRP into the lower airway. Spread to distal sites other than the larynx was reported to occur in about 30\% of children and about $16 \%$ of adults. ${ }^{4}$ Malignant changes were also rarely found, with 1.6\% reported in long-term follow-up. ${ }^{5}$

\section{LASER SURGERY}

The purpose of surgical treatment for RRP is to remove lesions while preserving normal anatomical structures. Since RRP is difficult to eradicate with a single operation and recurs frequently, it is a standard treatment principle to control the papilloma infection while maintaining airway patency by removing only visible papillomas with as few operations as possible. When the papillomas are located in the anterior or posterior commissure, care should be taken not to damage the normal mucosa during surgery to prevent anterior glottic web or laryngeal stenosis.

The representative surgical method is to remove the papilloma under a surgical microscope using $\mathrm{CO}_{2}$ lasers. $\mathrm{CO}_{2}$ lasers belong to the infrared spectra with wavelengths of $10,600 \mathrm{~nm}$. The focus diameter can be reduced to 200-250 $\mu \mathrm{m}$ using a micromanipulator, making microsurgery easier (Fig. 1). $\mathrm{CO}_{2}$ lasers are used by randomly moving the focal distance according to the usage mode. Lasers can cut tissue when they are focused and coagulate tissue when the focus is blurred. Generally, a laser power of 2 watts is used, and the super-pulse or ultra-pulse mode generates less carbonization than the continuous mode. When making an incision, pulling the tissue using laryngeal forceps or a suction tube to reduce heat damage and make a clean incision is recommended. When cutting tissue using lasers, the tissue is pulled using laryngeal forceps or suction to reduce heat damage and make a clean incision (Fig. 2).

The advantages of $\mathrm{CO}_{2}$ lasers are that it enables surgery without disturbing the surgical field of vision because contact with the instruments is not needed and it has a hemostatic effect on small vessels. Vocal ligaments and muscle damage caused by the thermal effect should be
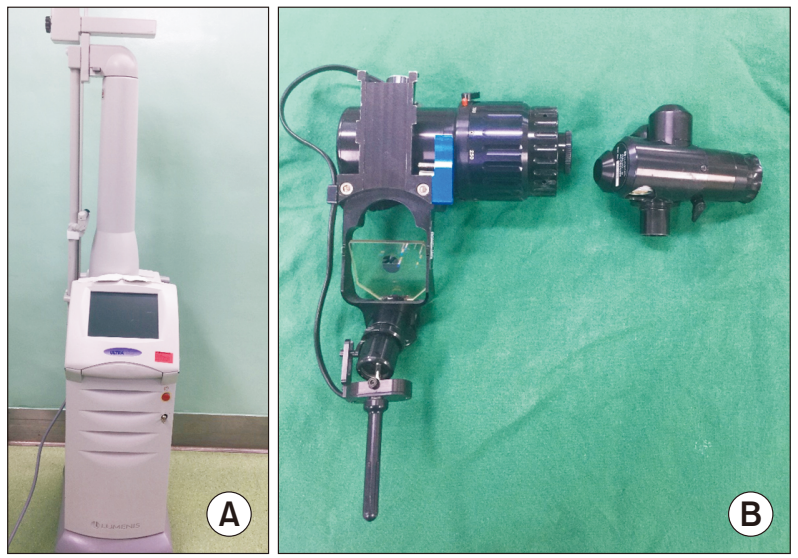

Fig. 1. $\mathrm{CO}_{2}$ laser system $(\mathrm{A})$ and micromanipulator (B). 

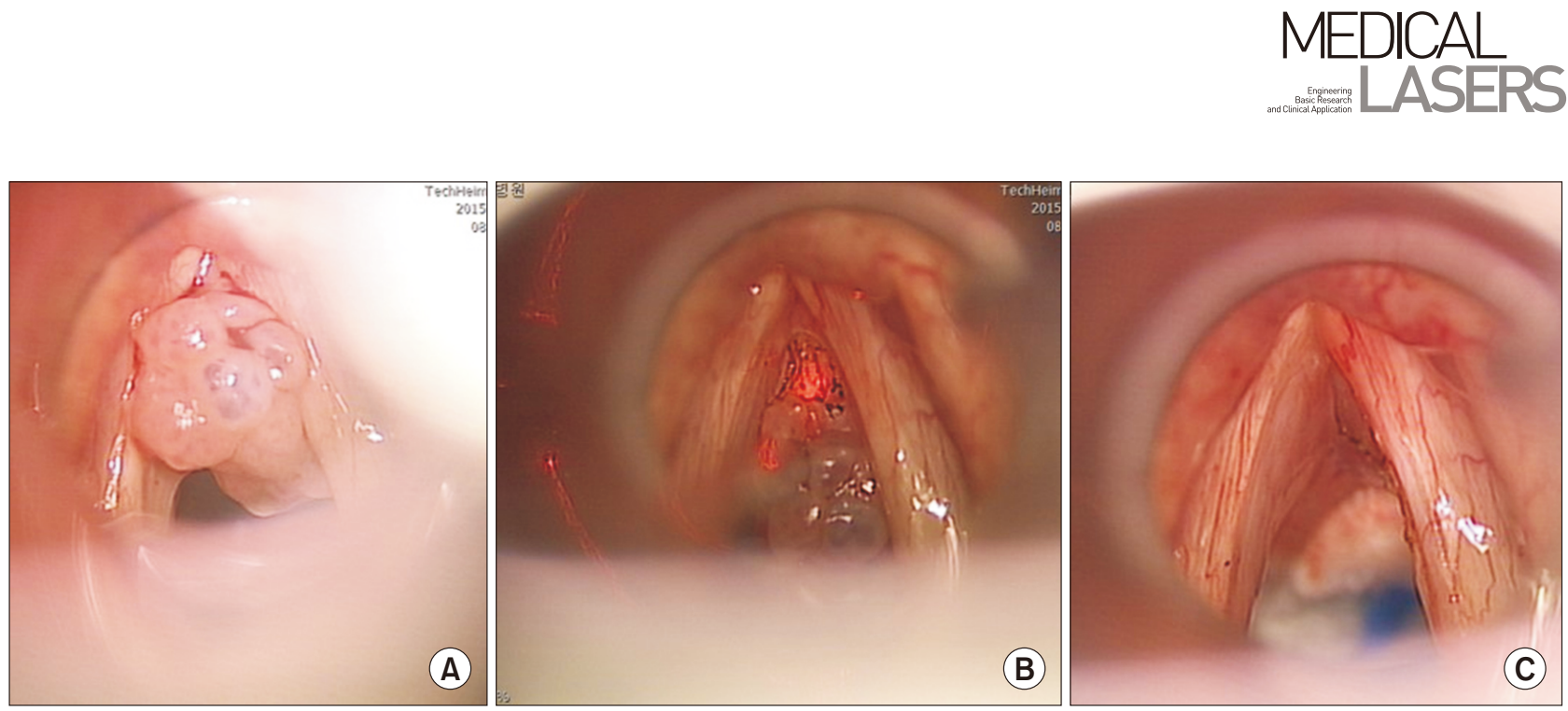

Fig. 2. $\mathrm{CO}_{2}$ laser surgery. (A) The papilloma was located at the left vocal fold. (B) The papilloma was removed using a $\mathrm{CO}_{2}$ laser while pulling the papilloma into the suction tube. (C) The papilloma was removed, preserving normal vocal fold tissue as much as possible.

avoided when vaporizing and removing papillomas, and if extensive spread to the larynx is present, vaporizing the supraglottis, glottis, and subglottis is recommended. If it is difficult to secure a surgical view due to the intubation tube, the tube can be removed with 100\% oxygen saturation, and when the oxygen saturation starts to drop, the intubation tube can be inserted through the lumen of the suspension laryngoscope to maintain an anesthetic state. This non-intubation method is possible for 2 - 3 minutes and close cooperation between the surgeon and the anesthesiologist is required. If the papillomas are located at the posterior portion of the larynx, the direct laryngoscope can be inserted behind the intubation tube to push the tube forward to secure the view. Other methods include the use of high-pressure jet ventilators attached to the suspension laryngoscope to safely remove papillomas located at the posterior glottic and subglottic areas. However, care must be taken not to place the tip of the jet ventilator deep below the vocal folds due to the risk of pneumothorax.

The disadvantages of $\mathrm{CO}_{2}$ lasers are laser burns and the risk of fire. Surgeons and patients wear laser goggles to prevent corneal injury. The patient's skin should be covered by gauze or a sterile surgical cloth soaked in water to protect against skin burns. In addition, filling the cuff of the intubation tube with colored saline can be used to detect damage to the cuff in advance. The cuff should be protected with cotton soaked with saline during surgery. Anesthesia gas should be kept at $40 \%$ or less oxygen tension and explosive gas such as nitrogen should be avoided. Other hazards include the viral DNA itself, which poses a potential risk of infection in the smoke generated during laser surgery. Therefore, the equipment should include an exhaust system that removes smoke quickly.

While $\mathrm{CO}_{2}$ lasers are most commonly used for the treatment of RRP, KTP lasers with $532 \mathrm{~nm}$ or pulsed dye lasers (PDLs) with a wavelength of $585 \mathrm{~nm}$ are also applied. KTP lasers or PDLs have good hemostatic effects because of the high absorption in hemoglobin, and outpatient procedures are possible without general anesthesia because lasers can be transmitted through thin optical fibers. ${ }^{7}$ KTP lasers or PDLs cause the necrosis of papillomas, which are rich in vascular tissue, by entirely irradiating the papillomas rather than resecting them.

\section{ADJUVANT TREATMENTS}

Although surgical removal is the main treatment method, adjuvant treatment is also considered if the papilloma recurs several times or occurs in a location where surgical removal is difficult such as the tracheobronchial tree. The criteria for adjuvant treatment are those requiring surgery more than four times a year, growing fast enough to cause airway stenosis, or lesions spread throughout the lower airway.'

\section{Cidofovir}

Cidofovir (Vistide ${ }^{\circledR}$ ) is a drug used for retinitis in AIDS patients caused by cytomegalovirus infection and was first used as adjuvant therapy for recurrent respiratory papillomas in $1995 .{ }^{8}$ Cidofovir is embedded in viral DNA and exerts an antiviral effect by inhibiting DNA transcription. Cidofovir was originally licensed for intravenous use and has shown nephrotoxicity and hypoglycemia side effects. Cidofovir use did not significantly increase malignancy in patients with RRP although carcinogenic and teratogenic 
effects were identified in an animal study.

An intralesional injection of cidofovir is currently the most commonly used adjuvant treatment for RRP. Chadha et al. reported a review of 17 articles that found that cidofovir was effective in more than $90 \%$ of the patients, with complete remission in $57 \%$ and partial remission in $35 \% .{ }^{10}$ In a randomized, double-blind, placebo-controlled study on the effects of cidofovir, McMurray et al. divided 19 patients into a treatment group with 10 patients and a control group with nine patients to compare severity scores, the voice handicap index (VHI), and the number of interventions for one year. The concentration of cidofovir used in the treatment group patients under 18 years of age was $0.3 \mathrm{mg} / \mathrm{mL}$, and $0.75 \mathrm{mg} / \mathrm{mL}$ in those over 18 years of age at the beginning of the study, followed by 5.0 $\mathrm{mg} / \mathrm{mL}$, regardless of age. The number of interventions was not different between the groups, at 2.9 in the treatment group and 3 in the control group. The severity score and $\mathrm{VHI}$ were significantly improved compared to the initial values in each group, but there was no significant statistical difference between the two groups. Therefore, the authors found no evidence that cidofovir was effective in the treatment of RRP. ${ }^{11}$

Cidofovir intralesional injection has the advantage of locally high concentrations without significantly increasing blood concentrations. However, the possibility of systemic complications should also be considered for these offlabel uses. The complications of off-label use can include nephrotoxicity, opthalmotoxicity, and neutropenia. ${ }^{12}$ To summarize the general opinion on intralesional injections of cidofovir, first, it is common to use it if surgery is required more than six times a year, the surgical intervals are short, or there is a large spread of papilloma in children. In addition, cidofovir use may be considered if papillomas are located in the anterior or posterior commissure, surgical treatment fails, or RRP occurs before the age of three. Second, a dose of 2.5 to $7.5 \mathrm{mg} / \mathrm{mL}$ is recommended, and the amount injected should be less than $4 \mathrm{~mL}$ for adults and adolescents, and less than 2 $\mathrm{mL}$ for infants and should not exceed $3 \mathrm{mg} / \mathrm{kg}$ in infants. Third, cidofovir treatment should be stopped in patients in complete remission. Fourth, performing a biopsy is recommended because of the possibility of malignant changes, and blood tests for renal function and neutrophil counts are not required unless the cidofovir dose exceeds $3 \mathrm{mg} / \mathrm{kg}^{13}$

The intravenous injection of cidofovir for RRP was reported in three cases, with interferon (IFN)- $\alpha$ in two cases, and with indole-3-carbinol in one case. ${ }^{14}$ The concentration of the intravenous injection was $5 \mathrm{mg} / \mathrm{kg}$ and was preceded by the oral administration of probenecid to prevent nephrotoxicity.

\section{Indole-3-carbinol}

Indole-3-carbinol (I3C) is a substance commonly found in cruciferous vegetables such as cabbage, broccoli, and kale and is known to have anti-cancer effects in breast cancer by its involvement in estrogen metabolism. In estrogen metabolism, I3C reduces the production of $16 \alpha$ -hydroxyestrone, which promotes DNA synthesis, induces the growth of epithelial cells, and increases the production of 2-hydroxyestrone, which has anti-proliferative effects. Vocal folds have estrogen receptors and laryngeal papillomas have a much greater estrogen-binding capacity than normal tissue. ${ }^{15}$

When laryngeal tissue infected with HPV11 was implanted into mice in an animal study, 100\% of the mice in the control group developed tumors, but only $25 \%$ of the mice in the $13 \mathrm{C}$-injected group developed tumors and a preventive effect was seen in $75 \%$ of the mice. ${ }^{16}$ Rosen et al. reported that 11 out of 33 patients with an average age of 48 years who took $200 \mathrm{mg}$ of I3C twice a day for an average of 50 months were completely cured at long-term follow-up. Ten patients with an average age of 38 years showed partial remission, took it for 39 months, and the interval of surgeries was increased from 3 months to 12.5 months after taking it. Twelve people with an average age of 29 years showed no improvement after taking I3C for an average of 21 months. ${ }^{17} \mathrm{I} \mathrm{C}$ is effective for prevention of recurrence and taking it after the complete removal of papillomas is preferred.

\section{Interferon}

Interferon began to be used in early 1980 as adjuvant therapy for RRP, and IFN- $\alpha$ is most commonly used. IFN- $\alpha$ increases the production of protein kinase and endonuclease to inhibit viral growth. ${ }^{18}$

There are controversial results on the effectiveness of IFN- $\alpha$ treatment. According to a study by Healy et al., the initial effect of papilloma inhibition comparing surgery alone with treatment combined with IFN- $\alpha$ was not maintained for more than two years, indicating that combination therapy was not beneficial compared to surgery alone. However, Leventhal et al. showed that IFN- $\alpha$ treatment was effective in $75 \%$ of the patients, and one-third of the patients were completely cured. ${ }^{19,20}$ Continuation of treatment is recommended if IFN- $\alpha$ is effective in the first six months and discontinued if IFN- $\alpha$ treatment is ineffective.

Side effects of IFN- $\alpha$ include flu-like symptoms such 


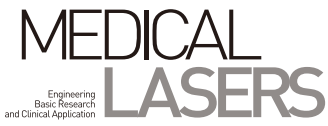

as fever, chills, and headaches during acute periods, and liver failure, leukocytosis, platelet count reductions, recessive convulsions, growth delays, rashes, and hair loss. Although the appropriate dose and duration of IFN- $\alpha$ administration vary from study to study, children are generally given a daily dose of $5 \times 10^{6}$ units $/ \mathrm{m}^{2}$ for the first 28 days, followed by the same dose three times a week for the next five months. If the effects are good and the side effects are not severe, the dose is reduced to three times a week, and then gradually reduced further until treatment is stopped.?

\section{Bevacizumab}

In immunohistochemical staining, vascular endothelial growth factor (VEGF) is expressed in the epithelium of papillomas. ${ }^{21}$ Bevacizumab (Avastin) is a monoclonal antibody that combines with VEGF to prevent the activation of VEGF. Bevacizumab has been used as intravenous injections for metastatic lung, colorectal, breast, kidney, and head and neck cancer, and low-concentration local injections have been successfully used for diseases such as macular degeneration. Bevacizumab can cause side effects such as hypertension, bleeding, and nephritis. However, the side effects of low-concentration local injections are very low at $0.21 \% .^{22}$

Zeitels et al. injected bevacizumab into the lamina propria of the vocal folds using laryngeal needles, along with $532 \mathrm{~nm}$ KTP laser surgery with good coagulative effects in 10 adult patients. Combination therapy showed a $90 \%$ decrease in the recurrence rate compared to KTP laser treatment only, and seven out of 10 people showed complete remission, and only three of them relapsed. Patients with recurrent or incomplete remission during periodic bevacizumab injections and KTP laser procedures at intervals of 8 to 12 weeks needed further surgery under general anesthesia. ${ }^{22}$ Maturo et al. treated three children with the combination therapy of KTP laser and bevacizumab. The voice and severity scores were decreased in two of the children, and cidofovir injections were performed in one due to repeated recurrences. ${ }^{23}$ Zeitels et al. treated 20 adult patients in an outpatient clinic using KTP lasers and bevacizumab. Three patients showed complete recovery, 16 patients showed improvement in disease, and the condition of only one patient worsened. In addition, voice quality was significantly improved compared to before treatment. ${ }^{24}$

\section{Acyclovir}

Acyclovir is activated by viral thymidine kinase and inhibits DNA polymerase, thus blocking the synthesis of
DNA. Acyclovir is effective for herpes simplex virus (HSV), varicella-zoster virus (VZV), Epstein-Barr virus (EBV), and cytomegalovirus (CMV), but does not directly affect HPV because HPV does not have thymidine kinase. However, acyclovir can be helpful in these patients because superinfection with other viruses, which is clinically severe, is common in patients with RRP. When acyclovir is administered orally as adjunctive therapy after laser surgery, the extent of disease and the recurrence rate were decreased..$^{25}$ However, there was a limitation in evaluating its effectiveness because there has been no case-control study.

\section{Ribavirin}

Ribavirin, a drug used to treat respiratory syncytial virus pneumonia in children, has been for RRP treatment after reports of its effectiveness in warts on the skin. McGlennen et al. gave ribavirin orally to four patients. There was no recurrence in two patients and minimal recurrence in two patients. Ballauf et al. reported improvement from ribarvirin oral administration in patients with severe recurrent respiratory papilloma who needed a tracheotomy. ${ }^{26,27}$ The side effects of ribavirin include hemolysis, thrombocytopenia, and leukopenia. There are limitations in assessing the effectiveness of ribavirin as only a few cases have been reported.

\section{Mumps vaccine}

Most children are vaccinated for mumps around the age of one year. While HPV is a DNA virus, mumps virus is an RNA virus belonging to paramyxoviruses and the two viruses have little in common. Pashley performed intralesional injection combined with $\mathrm{CO}_{2}$ laser surgery in patients with RRP, and in a preliminary study, nine of 11 patients improved with one to 10 injections, and 29 improved in a study of 38 patients. ${ }^{28}$ Mumps vaccine has the advantages of low cost, relative safety, and availability. However, since there were no controls and it was not a prospective randomized study, there is a limitation that it may be the result of chance, as the author also described. Furthermore, the theoretical basis for the mechanism of action is lacking.

\section{Cyclooxygenase-2 inhibitor}

Epidermal growth factor receptor (EGFR) is overexpressed in papilloma cells and is known to increase the expression of cyclooxygenase-2 (COX-2) through different channels in malignant tumors and benign papilloma. ${ }^{29}$ For this reason, a COX-2 inhibitor was tried on patients with RRP. 


\section{Photodynamic therapy}

Photodynamic therapy (PDT) is a method to treat cancer or nonmalignant pathologies using an irradiating laser with a suitable wavelength after the injection of a photosensitizer. Photosensitizers used in PDT are absorbed relatively more by tumor tissue than by normal tissue and are retained longer. The main mechanisms of treating tumors with PDT are direct cell damage by oxygen free radicals and vascular occlusion around the tumor, and the activation of the immune system against the tumor cells.

Shikowitz et al. have tried to treat the disease since 1988, after confirming that PDT was effective for papillomas in an animal study. As a photosensitizer, dihematoporphyrin-ether (DHE), a hematoporphyrin derivative, was used and intravenously injected 48 hours before surgery. A $630 \mathrm{~nm}$ wavelength dye laser was used as a light source, and the irradiation time was 100 to 200 seconds. A total of 48 people were treated with PDT, and 33 people in the control group received conventional treatment. In the treatment group, $\mathrm{CO}_{2}$ lasers were used minimally to secure the airway. As a result of treatment, the rate of papilloma growth in the first year in the PDT group decreased meaningfully, and the effect was maintained for three years. ${ }^{30}$ PDT using DHE reduced the RRP severity score by $50 \%$, but there was a problem with longstanding photosensitivity. Shikowitz et al. used a new photosensitizer, meso-tetra (hydroxyphenyl) chlorin (mTHPC, Foscan ${ }^{\circledR}$ ), which is absorbed more in papilloma than in normal tissue and excreted quickly, to treat PDT. A $652 \mathrm{~nm}$ wavelength diode laser was used as the light source and the irradiation time was 200 to 330 seconds. Fifteen patients completed treatment, and although there was an improvement in laryngeal lesions, the papillomas recurred within three to five years. Therefore, PDT using MTHPC induced an improvement in laryngeal lesions, but the healing condition was not maintained and the papillomas recurred, making it a less effective adjuvant therapy. ${ }^{31}$

\section{HPV vaccine}

A quadrivalent HPV vaccine (Gardasil; Merck) used for the purpose of preventing cervix cancer prevents infection with HPV 6, 11, 16, and 18. In women between the ages of 15 and 26, the HPV vaccine effectively prevented cervical and vulvovaginal tumors. ${ }^{32} \mathrm{HPV}$ vaccines are most effective when used before the individual is sexually active. Vaccines should be inoculated around the age of 11- 12, before sexual experience. However, if individuals are not vaccinated when they are young, vaccination before the age of 25 is recommended. It is thought that the HPV vac- cine will reduce the incidence of RRP as well, by reducing diseases caused by cervical or vulvovaginal HPV. In addition, a bivalent, instead of a quadrivalent vaccine, was developed to prevent HPV 16 and18, which is thought to have the effect of reducing the incidence of head and neck cancer. However, since RRP is mostly caused by HPV 6 and 11 , a bivalent vaccine is thought to be ineffective in preventing RRP.

\section{Acid reflux}

HPV, which remains dormant in the laryngeal mucosa, is considered one of the causes of frequent RRP relapse, and trauma or inflammatory reactions such as tracheostomy or acid reflux are thought to contribute to the activation of the virus. As squamous metaplasia occurs when the larynx mucosa comes into contact with acid or pepsin, and HPV is well-developed in the squamocolumnar junction, acid reflux promotes the progression of RRP. Meckena et al. reported that the treatment of acid reflux and improvement in RRP were related, and Bradford et al. reported that reflux treatment could reduce stenosis that could occur after laser surgery. ${ }^{33,34}$ Therefore, treating acid reflux in patients with RRP is recommended.

\section{CONCLUSIONS}

RRP is not a common disease but spread to the trachea or bronchus can cause serious life-threatening problems, and considerable additional effects such as dysphonia or airway stenosis can occur due to frequent recurrence. To date, there is no definitive treatment method and surgical removal is the primary treatment, preserving the normal tissue of the larynx as much as possible. However, if the disease recurs frequently, is located where additional effects are likely, or the severity of the disease is high, treatment in combination with adjuvant therapy is needed.

\section{REFERENCES}

1. Derkay CS, Wiatrak B. Recurrent respiratory papillomatosis: a review. Laryngoscope 2008;118:1236-47.

2. Wiatrak BJ, Wiatrak DW, Broker TR, Lewis L. Recurrent respiratory papillomatosis: a longitudinal study comparing severity associated with human papilloma viral types 6 and 11 and other risk factors in a large pediatric population. Laryngoscope 2004;114(11 Pt 2 Suppl 104):1-23.

3. Shah KV, Stern WF, Shah FK, Bishai D, Kashima HK. Risk factors for juvenile onset recurrent respiratory papillomatosis. Pediatr Infect Dis J 1998;17:372-6.

4. Schraff S, Derkay CS, Burke B, Lawson L. American Society of 
Pediatric Otolaryngology members' experience with recurrent respiratory papillomatosis and the use of adjuvant therapy. Arch Otolaryngol Head Neck Surg 2004;130:1039-42.

5. Dedo HH, Yu KC. CO(2) laser treatment in 244 patients with respiratory papillomas. Laryngoscope 2001;111:1639-44.

6. Kashima HK, Kessis T, Mounts P, Shah K. Polymerase chain reaction identification of human papillomavirus DNA in CO2 laser plume from recurrent respiratory papillomatosis. Otolaryngol Head Neck Surg 1991;104:191-5.

7. Rees CJ, Halum SL, Wijewickrama RC, Koufman JA, Postma GN. Patient tolerance of in-office pulsed dye laser treatments to the upper aerodigestive tract. Otolaryngol Head Neck Surg 2006;134:1023-7.

8. Van Cutsem E, Snoeck R, Van Ranst M, Fiten P, Opdenakker $G$, Geboes K, et al. Successful treatment of a squamous papilloma of the hypopharynx-esophagus by local injections of (S)1-(3-hydroxy-2-phosphonylmethoxypropyl)cytosine. J Med Virol 1995; $45: 230-5$.

9. Broekema FI, Dikkers FG. Side-effects of cidofovir in the treatment of recurrent respiratory papillomatosis. Eur Arch Otorhinolaryngol 2008;265:871-9.

10. Chadha NK, James AL. Antiviral agents for the treatment of recurrent respiratory papillomatosis: a systematic review of the English-language literature. Otolaryngol Head Neck Surg 2007;136:863-9.

11. McMurray JS, Connor N, Ford CN. Cidofovir efficacy in recurrent respiratory papillomatosis: a randomized, doubleblind, placebo-controlled study. Ann Otol Rhinol Laryngol 2008;117:477-83.

12. Gillen D. Direct healthcare professional communication regarding serious adverse reactions following off-label use of Vistide [Internet]. Great Abington: Gilead Sciences Limited; 2011. [cited 2011 Jan 12]. Available from: https://www.hpra.ie/ docs/default-source/Safety-Notices/dhcp-gilead-12-01-11. pdf?sfvrsn=0.

13. Derkay CS, Volsky PG, Rosen CA, Pransky SM, McMurray JS, Chadha NK, et al. Current use of intralesional cidofovir for recurrent respiratory papillomatosis. Laryngoscope 2013;123:705-12.

14. Armbruster C, Kreuzer A, Vorbach H, Huber M, Armbruster C. Successful treatment of severe respiratory papillomatosis with intravenous cidofovir and interferon alpha-2b. Eur Respir J 2001;17:830-1.

15. Essman EJ, Abramson A. Estrogen binding sites on membranes from human laryngeal papilloma. Int J Cancer 1984;33:33-6.

16. Newfield L, Goldsmith A, Bradlow HL, Auborn K. Estrogen metabolism and human papillomavirus-induced tumors of the larynx: chemo-prophylaxis with indole-3-carbinol. Anticancer Res 1993;13:337-41.
17. Rosen CA, Bryson PC. Indole-3-carbinol for recurrent respiratory papillomatosis: long-term results. J Voice 2004;18:248-53.

18. Leventhal BG, Kashima HK, Weck PW, Mounts P, Whisnant JK, Clark KL, et al. Randomized surgical adjuvant trial of interferon alfa-n1 in recurrent papillomatosis. Arch Otolaryngol Head Neck Surg 1988;114:1163-9.

19. Healy GB, Gelber RD, Trowbridge AL, Grundfast KM, Ruben RJ, Price KN. Treatment of recurrent respiratory papillomatosis with human leukocyte interferon. Results of a multicenter randomized clinical trial. N Engl J Med 1988;319:401-7.

20. Leventhal BG, Kashima HK, Mounts P, Thurmond L, Chapman S, Buckley $S$, et al. Long-term response of recurrent respiratory papillomatosis to treatment with lymphoblastoid interferon alfa-N1. Papilloma Study Group. N Engl J Med 1991;325:613-7.

21. Rahbar R, Vargas SO, Folkman J, McGill TJ, Healy GB, Tan X, et al. Role of vascular endothelial growth factor-A in recurrent respiratory papillomatosis. Ann Otol Rhinol Laryngol 2005;114:289-95.

22. Zeitels SM, Lopez-Guerra G, Burns JA, Lutch M, Friedman AM, Hillman RE. Microlaryngoscopic and office-based injection of bevacizumab (Avastin) to enhance 532-nm pulsed KTP laser treatment of glottal papillomatosis. Ann Otol Rhinol Laryngol Suppl 2009;201:1-13.

23. Maturo S, Hartnick CJ. Use of 532-nm pulsed potassium titanyl phosphate laser and adjuvant intralesional bevacizumab for aggressive respiratory papillomatosis in children: initial experience. Arch Otolaryngol Head Neck Surg 2010;136:561-5.

24. Zeitels SM, Barbu AM, Landau-Zemer T, Lopez-Guerra G, Burns JA, Friedman AD, et al. Local injection of bevacizumab (Avastin) and angiolytic KTP laser treatment of recurrent respiratory papillomatosis of the vocal folds: a prospective study. Ann Otol Rhinol Laryngol 2011;120:627-34.

25. Endres DR, Bauman NM, Burke D, Smith RJ. Acyclovir in the treatment of recurrent respiratory papillomatosis. A pilot study. Ann Otol Rhinol Laryngol 1994;103(4 Pt 1):301-5.

26. McGlennen RC, Adams GL, Lewis CM, Faras AJ, Ostrow RS. Pilot trial of ribavirin for the treatment of laryngeal papillomatosis. Head Neck 1993;15:504-12; discussion 512-3.

27. Balauff A, Sira J, Pearman K, McKiernan P, Buckels J, Kelly D. Successful ribavirin therapy for life-threatening laryngeal papillomatosis post liver transplantation. Pediatr Transplant 2001;5:142-4.

28. Pashley NR. Can mumps vaccine induce remission in recurrent respiratory papilloma? Arch Otolaryngol Head Neck Surg 2002;128:783-6.

29. Wu R, Coniglio SJ, Chan A, Symons MH, Steinberg BM. Upregulation of Rac1 by epidermal growth factor mediates COX2 expression in recurrent respiratory papillomas. Mol Med 2007;13:143-50.

30. Shikowitz MJ, Abramson AL, Freeman K, Steinberg BM, Nouri 
M. Efficacy of DHE photodynamic therapy for respiratory papillomatosis: immediate and long-term results. Laryngoscope 1998;10:962-7.

31. Shikowitz MJ, Abramson AL, Steinberg BM, DeVoti J, Bonagura VR, Mullooly V, et al. Clinical trial of photodynamic therapy with meso-tetra (hydroxyphenyl) chlorin for respiratory papillomatosis. Arch Otolaryngol Head Neck Surg 2005;131:99-105.

32. Garland SM, Hernandez-Avila M, Wheeler CM, Perez G, Harper DM, Leodolter $S$, et al. Quadrivalent vaccine against human papillomavirus to prevent anogenital diseases. N Engl J Med 2007;356:1928-43.

33. McKenna M, Brodsky L. Extraesophageal acid reflux and re- current respiratory papilloma in children. Int J Pediatr Otorhinolaryngol 2005;69:597-605.

34. Holland BW, Koufman JA, Postma GN, McGuirt WF Jr. Laryngopharyngeal reflux and laryngeal web formation in patients with pediatric recurrent respiratory papillomas. Laryngoscope 2002;112:1926-9.

How to cite this article: Woo SH, Chung PS, Lee SJ. Treatment of recurrent respiratory papillomatosis using laser and available adjuvant therapies. Med Lasers 2020;9:126-133. https://doi.org/10.25289/ML.2020.9.2.126 